\title{
Utility of a modified distress thermometer in screening COVID-19 patients for psychological distress: a prospective Egyptian study
}

\author{
Sherif A.A. Mohamed, ${ }^{1}$ Azza AbdelHafeez, ${ }^{2}$ Ehab Kamel, ${ }^{3}$ Alaa Rashad ${ }^{4}$ \\ ${ }^{1}$ Department of Chest Diseases and Tuberculosis, Faculty of Medicine, Assiut University, Assiut \\ ${ }^{2}$ Department of Medical Physiology, Faculty of Medicine, Assiut University, Assiut \\ ${ }^{3}$ Department of Psychiatry, Faculty of Medicine, Assiut University, Assiut \\ ${ }^{4}$ Department of Chest Diseases and Tuberculosis, Qena Faculty of Medicine, South Valley University, Qena, Egypt
}

Background: The National Comprehensive Cancer Network (NCCN) has adopted the distress thermometer (DT) as one of the best-known distress-screening instruments. We have adopted a modified version of the NCCN distress thermometer. We questioned if this modified DT (m-DT) could be utilized for measuring the prevalence of psychological distress among COVID-19 patients.

Methods: The prospective study included 2 phases; modification of the original DT and its associated problem list (PL), and evaluation of this m-DT in measuring the prevalence of psychological distress among COVID-19 patients. Egyptian adult subjects with suspected or confirmed cases of COVID-19 at 2 University Hospitals were enrolled. Binary logistic regression tests were carried out to explore the association between the m-DT cut-off scores of 4 and the clinical variables.

Results: One hundred sixty-nine $(60.4 \%)$ patients experienced significant distress (m-DT cut off score $\geq 4$ ). Logistic regression showed that occupation, presence of special habits, length of quarantine time, worry, cough, shortness of breath, and fever, were independent factors associated with significant distress in COVID-19 patients.

Conclusion: With the modified distress thermometer (m-DT), 60\% of Egyptian COVID-19 patients experienced significant distress. This distress was significantly related to age, marital status, occupation, presence or absence of special habits, and length of the quarantine time. With m-DT, the current study had identified worry, being a health-care worker, shortness of breath, fever, length of quarantine time, presence of special habits, and cough as independent factors associated with significant distress in COVID-19 patients. Further studies are warranted.
\end{abstract}

Key words: COVID-19; modified; distress thermometer; problem list; screening; Egypt; psychological.

Correspondence: Dr. Sherif A. A. Mohamed, Associate Professor of Pulmonary Medicine. Department of Chest Diseases and Tuberculosis, Faculty of Medicine, Assiut University, 71516 Assiut, Egypt.

Tel. +20.88.241371, +20.966.538618846 - Fax: +20.88.241333327. E-mail: saawm220@gmail.com

Contributions: All authors have provided approval of the manuscript to be published and have agreed to be accountable for all aspects of the work in ensuring that questions related to the accuracy or integrity of any part of the work are appropriately investigated and resolved. SAAM, AR, EK, contributed to the draft of the submitted article, revised it critically for important content, and made substantial contributions to conception and design, as well as data acquisition, analysis, and interpretation; SAAM, AR, AA contributed to the draft of the submitted article and made substantial contributions to acquisition, analysis, and interpretation of clinical and physiological data.

Conflict of interest: The authors declare that they have no competing interests, and all authors confirm accuracy.

Funding: This research did not receive any specific grant from funding agencies in the public, commercial, or not-forprofit sectors.

Availability of data and material: The datasets used and/or analyzed during the current study are available from the corresponding author on reasonable request.

Ethics approval and consent to participate: Ethical approval was obtained from the Institutional Review Boards of the Faculty of Medicine of both South Valley and Assiut Universities. A written consent was obtained from the study subjects before carrying out the screening

Consent for publication: Not applicable. 


\section{Introduction}

It is already evident that the direct and indirect psychological and social effects of the coronavirus disease 2019 (COVID-19) pandemic are pervasive and could affect mental health now and in the future. The mental health sequelae associated with the pandemic could be observed in clinicians who care for patients with suspected and confirmed cases of COVID-19, patients with COVID19 and their families, patients with established psychiatric disorders, as well as the general population [1]. The potential fallout of an economic downturn, as well as the consequences of quarantine and associated social and physical distancing measures, are additional risk factors for mental health problems [1-3].

The presence of significant distress in certain groups of patients e.g. cancer patients, which may remain unrecognized, motivated many international regulatory organizations and professional societies [(e.g., International Psycho-Oncology Society (IPOS), National Institute for Health and Care Excellence (NICE) and National Comprehensive Cancer Network (NCCN)] to recommend the routine screening and management of distress as an integral aspect of whole-person cancer care in the same way that health-care teams monitor and respond to other vital signs [4,5]. The NCCN has adopted the distress thermometer (DT) as one of the best-known distress-screening instruments [4]. DT is a singleitem, self-report measure of distress that provides a brief, visual analog, non-invasive, valid, and acceptable alternative to longer and more burdensome psychometric instruments. Besides, the problem list (PL) can be used with the DT to provide words for psychological problems with non-stigmatizing connotations to identify possible contributing factors [4].

Despite the apparent simplicity of the DT, it covers most-if, not all- problems that might be faced by any study population (populations with different racial, religious, social, and financial aspects), and worldwide. So, it is not surprising that DT has been successfully translated from English into several languages [6]. Because of its simplicity and easy application, DT has been used to screen non-cancer patients, as well. It proved effective in patients with chronic respiratory disorders [7] and bone marrow transplant patients [8].

With these fore-mentioned advantages of DT, it is thought that it can represent a useful tool to screen populations facing COVID19 [3]. They include the frontline clinicians and nurses dealing with patients, the COVID-19 patients themselves, as well as the general populations. Being a simple and rapid test that can be used by medical or para-medical personnel it will help manage psychological disorders among those populations promptly, which is of paramount significance in the era of pandemics. Therefore, in the current study, we have adopted a modified version of the NCCN distress thermometer (m-DT) and its PL to be compatible with the nature of COVID-19. We hypothesized that this modified version could be a "tailored model" for the original DT. Being addressing only emotional and physical problems closely related to the signs and symptoms of COVID-19, we thought that this m-DT will target the point of being "more disease-specific", and in a timelymanner. The primary outcome was to assess the validity of such a tool in the new COVID-19 pandemic. The secondary outcome was to evaluate the utility of this modified DT (m-DT) in measuring the prevalence of psychological distress among COVID-19 patients.

\section{Materials and Methods}

\section{Study design}

The study comprised 2 phases: Phase I, modification of the original NCCN distress thermometer and problem list into a compatible version for patients with COVID-19, and Phase II, evaluation of this modified DT in measuring the prevalence of psychological distress among enrolled COVID-19 patients.

\section{Phase I: Modification of the original DT and PL}

Distress is defined by the NCCN panel as a "multifactorial unpleasant emotional experience of a psychological (cognitive, behavioral, emotional), social, and/or spiritual nature that may interfere with the ability to cope effectively with cancer, its physical symptoms, and its treatment" [4]. Distress extends along a continuum, ranging from common normal feelings of vulnerability, sadness, and fears to problems that can become disabling, such as depression, anxiety, panic, social isolation, and existential and spiritual crisis [4]. DT has been recommended by the NCCN in its Clinical Practice Guidelines in Cancer Distress Management [4]. DT is a single-item, self-report measure of distress that provides a brief, visual analog, non-invasive, valid, and acceptable alternative to longer and more burdensome psychometric instruments. Also, the PL can be used with the DT to provide words for psychological problems with non-stigmatizing connotations to identify possible contributing factors $[4,6]$. The PL offers the advantage of being brief enough to be easy for health professionals to use in daily practice. A written permission from the NCCN to modify its DS and PL, to be used in the current study, was obtained. To be more compatible and easily usable in patients with COVID-19, the original DS and PL of the NCCN were modified. Three principal modifications were carried out: first, the original NCCN scheme contained 5 kinds (domains) of problems (i.e. practical, family, emotional, spiritual/religious concerns, and physical); the modified scheme contains only 2 domains of problems (emotional and physical). Second, the original scheme emotional PL remained the same in the modified one, while the physical PL was modified to contain 16 problems/symptoms related to COVID-19. Third, the duration at which subjects are asked about these problems was reduced to the past last 3 days, instead of one week at the original one. Figure 1 shows the modified DT and PL scheme used in the current study.

\section{Phase II: Evaluation of the m-DT in assessing distress}

The modified DS and PL were then used. The cutoff score of $\geq 4$ for significant distress adopted by the recently validated Arabic version of DT [6,9] was used for screening COVID-19 patients of the current study for distress. The screening was carried out for those patients at their first out-patient visit or inpatient admission. Patients were asked to rate their distress in the past 3 days on an 11 -point visual analog scale ranging from 0 (no distress) to 10 (extreme distress) (Figure 1). Patients were then asked to fill in PL that accompanies the visual image of the DT to check, whether or not (yes/no) they have any of the problems listed during the previous 3 days. For illiterate patients, a research assistant helped them to rate their distress and fill in the PL. Correlation between the PL and DT was carried out to identify the nature of distress and related factors.

\section{Study population}

Ethical approval was obtained from the Institutional Review Boards of the Faculty of Medicine of both South Valley and Assiut Universities. A written consent was obtained from the study subjects before carrying out the screening. 
Egyptian adult ( $\geq 18$ years old) subjects who fulfilled the criteria of suspected or confirmed case of COVID-19 [10] and managed as outpatients (at the respiratory triage) or admitted at the South Valley or Assiut University Hospitals at isolation medical wards with an adequate command of speaking and reading the Arabic language were enrolled into this study. Subjects who had a history of or undergoing treatment for psychiatric illness were excluded. Standard sociodemographic data were collected including age, marital status, education level, and employment status. The study objectives and procedure were fully explained to eligible patients. The essential infection control precautions for handling patients with COVID-19 were undertaken and the person who carried out the questionnaire wore full personal protective equipment (PPE) [10].

\section{Statistical analysis}

The Statistical Package for Social Science; SPSS, version 24 (SPSS Inc., Chicago, IL, USA) has been used for data analysis. The mean score, the standard deviation, the median score, and the frequency distribution of the DT have been explored using descriptive statistical analysis. All p-values were two-tailed. A p $<0.05$ was considered statistically significant. Binary logistic regression test was carried out to explore the association between the m-DT cutoff scores of $4[6,9]$ and the demographic and clinical variables, while binary and multivariable logistic regression tests were used to analyze the association between the m-DT cut-off scores and individual items in the PL.

\section{Results}

\section{Sociodemographic and clinical characteristics}

A total of 280 patients were prospectively enrolled. The median age was 39 (range 19-76) years. Females constituted $35.7 \%$ of the participants. Health-care workers represented $46.4 \%$ of the cohorts. Forty-one percent of patients had associated medical comorbidities. Despite that there were no significant differences between those with and without medical comorbidities $(\mathrm{p}=0.107)$, there was a significant difference between those with and without chronic respiratory disease. Eighty-three percent (65/78) with chronic respiratory diseases had significant distress, compared to $33 \%(6 / 18)$ in those without, $p=0.003$. Table 1 details these data.

\section{Data from m-DT and PL analysis}

One hundred sixty-nine $(60.4 \%)$ patients experienced significant distress ( $m$-DT cut off score $\geq 4$ ). The patients' average m-DT score was 4.2. There were significant differences between patients

\section{Modified Distress Thermometer and Problem List for COVID-19 Patients}

\section{DISTRESS THERMOMETER}

Distress is an unpleasant experience of a mental, physical, social, or spiritual nature. It can affect the way you think, feel, or act. Distress may make it harder to cope with having COVID-19 and/or its symptoms

Instructions: Please circle the number $(0-10)$ that best describes how much distress you have been experiencing in the past 3 days including today.

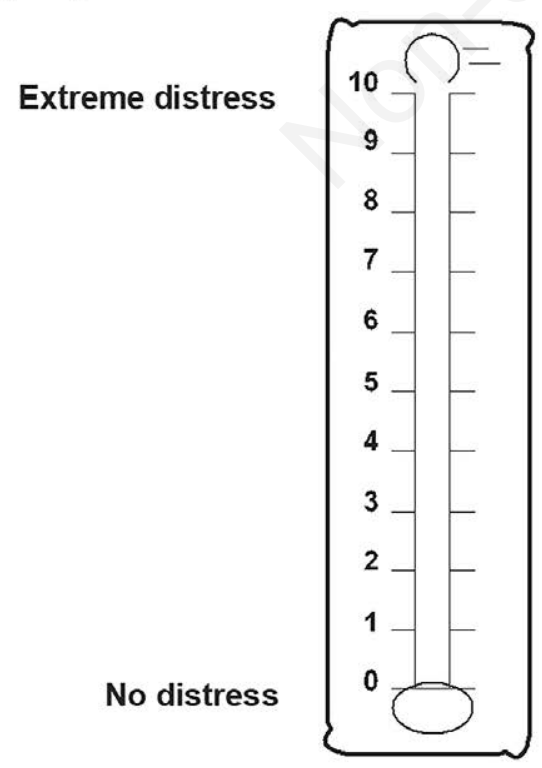

\section{PROBLEM LIST}

Please indicate if any of the following has been a problem for you in the past 3 days including today.

Be sure to check YES or NO for each.

YES NO Emotional Problems

प D Depression

व $\mathrm{F}$ Fears

a Nervousness

प $\square$ Sadness

a Worry

- L Loss of interest in usual activities

YES NO Physical Problems

a Cough

a Shortness of breath

व Sore throat

व Headache

व Chest pain

๑ A Anosmia

\ Myalgia

口 D Diarrhea

๑ $\square$ Eating/Anorexia

๑ $\square$ Fatigue

a $a$ Fever

\ Memory/concentration

a $\square$ Nausea/vomiting

- - Nose dry/congested

a Pain/Body aches

घ S Sleep 
with significant distress ( $m$-DT cut off score $\geq 4$ ) and those without significant one; with regards to mean age $(p=0.042)$, age groups $(\mathrm{p}=0.000)$, marital status $(\mathrm{p}=0.004)$, occupation $(\mathrm{p}=0.000)$, presence or absence of special habits $(\mathrm{p}=0.019)$, and length of the quarantine time $(\mathrm{p}=0.000)$. Table 1 shows these differences. The most frequent problems reported on the practical domain of the PL are shown in Table 2, in descending order, fever (67.5\%), cough $(59.3 \%)$, fears $(58.6 \%)$, and both fatigue and shortness of breath $(56.4 \%)$.

\section{Association between m-DT and both the sociodemo- graphics and PL items}

Binary logistic regression showed that m-DT score of 4 or more had statistically significant associations with 7 items: occupation, presence of special habits, length of quarantine time, worry, cough, shortness of breath, and fever.

After adjustment to the sociodemographic and clinical characteristics, the multivariable analysis confirmed that the same items were independent factors associated with significant distress in COVID-19 patients. The adjusted odds ratios (95\% confidence interval) for these items were: 9.096 (3.535-23.408), 7.767 (3.090$19.523), 5.184$ (2.112-12.724), 4.446 (1.747-11.316), 3.663 (1.523-8.815), 3.113 (1.256-7.715), and 2.842 (1.183-6.831), for worry, occupation, shortness of breath, fever, length of quarantine time, presence of special habits, and cough, respectively. Table 3 shows these associations.

\section{Discussion}

In the current study, we had tested a modified version of the original NCCN distress thermometer and its PL for measurement of distress among a well-characterized group of COVID-19 patients. Results showed that $60 \%$ of the screened subjects had experienced significant distress that is related to 7 different items closely related to the sociodemographic features as well as physical and emotional factors of the study cohorts.

The original DT is a single-item tool using a point Likert scale resembling a thermometer, where the patient rates his/her level of distress over the past week $[5,11]$. The NCCN Problem List for

Table 1. Sociodemographic characteristics of the study subjects $(\mathrm{n}=280)$ and their association with the modified distress thermometer (m-DT) score $\geq 4^{*}$.

\begin{tabular}{|c|c|c|c|c|}
\hline $\begin{array}{r}\text { Characteristic } \\
\text { n=280 (\%) }\end{array}$ & $\begin{array}{c}\text { Overall } \\
n=169(\%)\end{array}$ & m-DT cutoff $\geq 4$ & $\begin{array}{c}\text { m-DT cutoff }<4 \\
n=111(\%)\end{array}$ & $\mathbf{p}$ \\
\hline $\begin{array}{l}\text { Age in years } \\
\text { Median (range) } \\
\text { Mean } \pm \text { SD }\end{array}$ & $\begin{array}{r}39.00(19-76) \\
43.13 \pm 18.34\end{array}$ & $45.33 \pm 18.35$ & $36.66 \pm 16.83$ & 0.042 \\
\hline $\begin{array}{l}\text { Age groups } \\
\quad<40 \text { years } \\
>40 \text { years }\end{array}$ & $\begin{array}{l}142(50.7) \\
138(49.3)\end{array}$ & $\begin{array}{l}70(41.4) \\
99(58.6)\end{array}$ & $\begin{array}{l}72(64.9) \\
39(35.1)\end{array}$ & 0.000 \\
\hline $\begin{array}{l}\text { Gender } \\
\text { Female } \\
\text { Male }\end{array}$ & $\begin{array}{l}100(35.7) \\
180(64.3)\end{array}$ & $\begin{array}{c}62(36.7) \\
107(63.3)\end{array}$ & $\begin{array}{l}38(34.2) \\
73(65.8)\end{array}$ & 0.704 \\
\hline $\begin{array}{l}\text { Marital status } \\
\text { Single } \\
\text { Married } \\
\text { Divorced } \\
\text { Widow }\end{array}$ & $\begin{array}{c}136(48.6) \\
121(43.2) \\
12(4.2) \\
11(4.0)\end{array}$ & $\begin{array}{c}68(40.2) \\
85(50.3) \\
7(4.5) \\
9(5.0)\end{array}$ & $\begin{array}{c}68(61.3) \\
36(32.4) \\
5(4.5) \\
2(2.2)\end{array}$ & 0.004 \\
\hline $\begin{array}{l}\text { Educational level } \\
\text { Non-educated } \\
\text { Educated }\end{array}$ & $\begin{array}{c}65(23.2) \\
215(76.8)\end{array}$ & $\begin{array}{c}43(25.5) \\
126(74.5)\end{array}$ & $\begin{array}{l}22(20.0) \\
89(80.0)\end{array}$ & 0.313 \\
\hline $\begin{array}{l}\text { Occupation } \\
\text { Non-health care worker } \\
\text { Health care worker }\end{array}$ & $\begin{array}{l}150(53.6) \\
130(46.4)\end{array}$ & $\begin{array}{c}62(36.7) \\
107(63.3)\end{array}$ & $\begin{array}{l}88(79.3) \\
23(20.7)\end{array}$ & 0.000 \\
\hline $\begin{array}{l}\text { Special habits } \\
\text { No special habits } \\
\text { Smoking } \\
\text { Alcohol } \\
\text { Substance abuse } \\
\text { Smoking+ substance }\end{array}$ & $\begin{array}{c}107(38.2) \\
122(43.6) \\
13(5.2) \\
15(5.0) \\
23(8.0)\end{array}$ & $\begin{array}{r}51(30.2) \\
84(50.0) \\
9(4.8) \\
10(6.0) \\
15(9.0)\end{array}$ & $\begin{array}{c}56(50.0) \\
38(34.2) \\
4(4.3) \\
5(4.5) \\
8(7.0)\end{array}$ & 0.019 \\
\hline $\begin{array}{l}\text { Length of quarantine } \\
\qquad \begin{array}{l}<3 \text { months } \\
>3 \text { months }\end{array}\end{array}$ & $\begin{array}{l}128(45.7) \\
152(54.3)\end{array}$ & $\begin{array}{c}49(29.0) \\
120(71.0)\end{array}$ & $\begin{array}{l}79(71.2) \\
32(28.8)\end{array}$ & 0.000 \\
\hline $\begin{array}{l}\text { Underlying chronic disease } \\
\text { Present } \\
\text { Absent }\end{array}$ & $\begin{array}{l}116(41.4) \\
164(58.6)\end{array}$ & $\begin{array}{l}77(45.6) \\
92(54.4)\end{array}$ & $\begin{array}{l}39(35.0) \\
72(65.0)\end{array}$ & 0.107 \\
\hline
\end{tabular}

${ }^{*} \mathrm{~m}$-DT; modified distress thermometer. For age, data are expressed in mean \pm standard deviation and $\mathrm{t}$-test with $95 \%$ confidence interval was carried out to compare age between the 2 groups of $\mathrm{m}$ DT cut-off $<4$ and $\geq 4$. For other sociodemographic characteristics, data are expressed in numbers and percent and Chi-square tests was used to compare the significance of differences between the 2 groups of m-DT cut-off $<4$ and $\geq 4$. 
patients is a 39-item supplemental list of potential sources of distress that is incorporated as an essential part of the assessment to assist the provider in identifying distress. As this PL provides a comprehensive list of categories, it covers almost all aspects that might attribute to distress among cancer patients [4-6,9,11]. Despite these advantages, we had speculated that modifying this DT and its PL into a more practical and less-time consuming list of only emotional and physical items directly related to the impacts of COVID-19 would reproduce a more valid and utilizable tool for assessment of the rapidly growing global pandemic of COVID-19.

With this modified DT, our results had revealed a high prevalence $(60 \%)$ of distress among COVID-19 patients. Being a novel global illness, no one is immune [12-14], several aspects of this disease are still vague in the eye of the general population, affecting many body organs and systems $[15,16]$, and still has no definitive therapy, COVID-19 represents a real stressful condition and explains the high prevalence of distress among our cohort.

In the current study, a m-DT cutoff score of 4 correctly identi-
Table 2. The most frequent problem list items among the studied patients $(\mathbf{n}=\mathbf{2 8 0})$.

\begin{tabular}{lcc}
\hline iProblem list & No. of patients & $\%$ \\
Fever & 189 & 67.5 \\
Cough & 166 & 59.3 \\
\hline Fears & 164 & 58.6 \\
Fatigue & 158 & 56.4 \\
\hline Shortness of breath & 158 & 56.4 \\
Worry & 157 & 56.0 \\
\hline Anosmia & 149 & 53.2 \\
Headache & 119 & 42.5 \\
\hline Myalgia & 116 & 41.4 \\
Pain/body aches & 104 & 37.0 \\
\hline Chest pain & 95 & 34.0 \\
Nose dry/congested & 90 & 32.0
\end{tabular}

Table 3. Association between the m-DT score $\geq 4$ and both the socio-demographic factors and problem list items of COVID-19 patients.

\begin{tabular}{|c|c|c|c|c|c|}
\hline Problem list & $\begin{array}{c}\text { Item present } \\
(\%)\end{array}$ & $\begin{array}{c}\text { m-DT cut-off } \geq 4 \\
n=169(\%)\end{array}$ & $\begin{array}{c}\text { m-DT cutoff }<4 \\
n=111(\%)\end{array}$ & OR (95\% CI) & Adjusted OR (95\% CI) \\
\hline \multicolumn{6}{|l|}{ Sociodemographic factors } \\
\hline Age groups (>40 y) & $138(49)$ & $99(59)$ & $39(35)$ & $1.238(0.293-5.233)$ & \\
\hline Gender (male) & $180(64)$ & $107(63)$ & $73(66)$ & $0.895(0.280-2.861)$ & \\
\hline Marital status (unmarried) & $159(57)$ & $84(50)$ & $75(68)$ & $1.238(0.252-6.089)$ & \\
\hline Educational (non-educated) & $65(23)$ & $43(25)$ & $22(20)$ & $2.791(0.723-10.776)$ & \\
\hline Occupation (HC workers) & $130(46)$ & $107(63)$ & $23(21)$ & $15.99(4.604-55.533)^{* * *}$ & $7.767(3.090-19.523)^{* * *}$ \\
\hline Special habits (present) & $180(64)$ & $126(74)$ & $54(49)$ & $5.969(1.741-20.466)^{* *}$ & $3.113(1.256-7.715)^{*}$ \\
\hline \multicolumn{6}{|l|}{ Length of quarantine } \\
\hline (>3 months) & $152(54)$ & $120(71)$ & $32(29)$ & $7.573(2.328-24.633)^{* * *}$ & $3.663(1.523-8.815)^{* *}$ \\
\hline Chronic disease (present) & $116(41)$ & $77(45)$ & $39(35)$ & $2.109(0.607-7.324)$ & \\
\hline \multicolumn{6}{|l|}{ Emotional problems } \\
\hline Depression & $84(30)$ & $42(25)$ & $42(38)$ & $2.093(0.569-7.692)$ & \\
\hline Fears & $164(58)$ & $117(69)$ & $47(42)$ & $0.588(0.153-2.263)$ & \\
\hline Nervousness & $88(31)$ & $68(40)$ & $20(18)$ & $1.399(0.366-5.342)$ & \\
\hline Sadness & $44(16)$ & $25(15)$ & $19(17)$ & 3.347 (0.684-16.377) & \\
\hline Worry & $157(56)$ & $140(83)$ & $17(15)$ & $18.236(4.939-67.329)^{* * *}$ & $9.096(3.535-23.408) * * *$ \\
\hline Loss of interest & $61(22)$ & $36(21)$ & $25(23)$ & $0.227(0.048-1.065)$ & \\
\hline \multicolumn{6}{|l|}{ Physical problems } \\
\hline Cough & $166(59)$ & $124(73)$ & $42(38)$ & $5.445(1.754-16.901)^{* *}$ & $2.842(1.183-6.831)^{*}$ \\
\hline Shortness of breath & $158(56)$ & $138(82)$ & $20(18)$ & $7.137(2.110-24.140)^{* *}$ & $5.184(2.112-12.724)^{* * *}$ \\
\hline Sore throat & $54(19)$ & $39(23)$ & $15(14)$ & $0.978(0.203-4.703)$ & \\
\hline Headache & $119(42)$ & $70(41)$ & $49(44)$ & $1.758(0.597-5.183)$ & \\
\hline Chest pain & $95(34)$ & $63(37)$ & $32(29)$ & $0.754(0.226-2.518)$ & \\
\hline Anosmia & $149(53)$ & $99(58)$ & $50(45)$ & $1.637(0.510-5.252)$ & \\
\hline Myalgia & $116(41)$ & $70(41)$ & $46(41)$ & $0.934(0.332-2.626)$ & \\
\hline Diarrhea & $53(19)$ & $34(20)$ & $19(18)$ & 3.068 (0.761-12.367) & \\
\hline Eating/anorexia & $46(16)$ & $34(20)$ & $12(11)$ & $2.901(0.569-14.800)$ & \\
\hline Fatigue & $158(56)$ & $106(63)$ & $52(46)$ & $0.401(0.101-1.595)$ & \\
\hline Fever & $189(67)$ & $152(90)$ & $37(33)$ & $5.540(1.688-18.184)^{* *}$ & $4.446(1.747-11.316)^{* *}$ \\
\hline Memory/concentration & $38(13)$ & $21(12)$ & $17(15)$ & $0.825(0.182-3.739)$ & \\
\hline Nausea/vomiting & $47(17)$ & $37(22)$ & $10(9)$ & $1.114(0.201-6.165)$ & \\
\hline Nose dry/congested & $90(32)$ & $55(33)$ & $35(32)$ & $0.626(0.172-2.278)$ & \\
\hline Pain/body aches & $104(37)$ & $66(39)$ & $38(34)$ & $0.679(0.202-2.286)$ & \\
\hline Sleep & 75 (27) & $52(31)$ & $23(21)$ & $0.711(0.189-2.672)$ & \\
\hline
\end{tabular}

$\mathrm{OR}$, odds ratio; $\mathrm{CI}$, confidence interval; $\mathrm{HC}$, health-care; ${ }^{*} \mathrm{p}<0.05 ;{ }^{* *} \mathrm{p}<0.01 ;{ }^{* * *} \mathrm{p}<0.001$. 
fied $60 \%$ of patients as distressed. We propose using a cutoff score of 4 , which brings in an optimal combination of sensitivity and specificity, in order to avoid over-misdiagnoses due to false positive results. High false positive screening results may burden nondistressed patients with unnecessary interventions. For the original DT, the NCCN recommends using a score of 4 or higher as a sign for a clinically significant distress level [4]. However, other studies have validated the score of 5 as an optimal cutoff point [17], while others used the score of 3 [18]. There are no conclusive data regarding the optimal cutoff point because a single cutoff score that clearly maximizes the accuracy of the DT has not been found yet [19].

COVID-19 can be associated with multiple mental affections in several groups, including patients with COVID-19 and in clinicians who care for patients with suspected or confirmed COVID19 [1]. Besides, COVID-19 may adversely affect patients who have psychiatric disorders predating the pandemic [20]. Despite the rapid global spread of COVID-19, only a few cross-sectional, self-report surveys from January to April 2020 addressed the psychological impacts of the pandemic [1,2,21,22]. These studies observed that clinically significant symptoms of anxiety, depression, distress, and PTSD were present in up to $36 \%$ of adults with COVID-19. Moreover, no consistent predictors of mental illness in adults with COVID-19 have been identified. Results from these studies could be precluded by the convenience sampling methods necessary to rapidly generate and publish data [23].

Two online surveys in the United States were carried out, in March and April 2020, on representative samples of ( $\mathrm{n}>1000)$, and ( $\mathrm{n}>1400$ ); psychological distress was present in $36 \%$ [24] and $14 \%$ of them [25], respectively. In comparison to these figures, the recorded higher prevalence of distress in the current study could be attributable to different sociodemographic, population, and education characteristics. Characteristically, health-care workers represented $46.4 \%$ of our study cohorts. Psychological symptoms and disorders can occur in clinicians exposed to COVID-19. Previous reports from China [1] and Italy [26] had shown a prevalence of moderate to severe symptoms among hospital-based physicians and nurses, and frontline and second-line health care workers, respectively. These symptoms included anxiety (12-20\%), depression (15-25\%), insomnia (8\%), and traumatic distress (35-49\%), respectively $[1,26]$.

A review of 59 studies of viral outbreaks had identified multiple risk factors for psychological problems in health care workers [27]. The most consistent risk factor across studies was increased contact with affected patients. Other predictors were a prior history of psychiatric symptoms/disorders and/or general medical illnesses, spending a prolonged time in quarantine, and perceived lack of organizational support [27]. The most frequent problems reported on the practical domain of the PL were, in descending order, fever $(67.5 \%)$, cough $(59.3 \%)$, fears $(58.6 \%)$, and both fatigue and shortness of breath $(56.4 \%)$. It is noticed that these problems were a mix of emotional and COVID-19-related ones. This reflects the practicality and reproducibility of the used modified DT.

Results of the current study had shown that worry, being a health-care worker, shortness of breath, fever, length of quarantine time, presence of special habits, and cough were independent factors associated with significant distress in COVID-19 patients. These results are in agreement with those reported for the COVID19 pandemic [1,2,21-23], as well as those examined psychiatric problems in patients hospitalized for severe acute respiratory syndrome (SARS) or Middle East respiratory syndrome (60 studies, $\mathrm{n}$ $>2500$ cases) [22]. The later one found that during acute infection, $20-40 \%$ of patients manifested neuropsychiatric symptoms consistent with delirium like insomnia (42\%), impaired concentration
$(38 \%)$, anxiety (36\%), memory impairment $(33 \%)$, depressed mode $(33 \%)$, and confusion $(28 \%)$.

Our results highlight the importance of protecting healthcare and frontline workers exposed to suspected or confirmed COVID19 patients. Reports had shown that the most consistent factor that decreased the risk of adverse psychological outcomes in health care workers was access to personal protective equipment. Other consistent protective factors included having supportive peers, access to psychological interventions, and trust in the institution's infection control measures, receiving clear communication from supervisors, and adequate time off from work [27]. On the other hand, our results support those reports that attribute the mental symptoms and disorders that arise during the COVID-19 pandemic to biologic [28] and psychosocial factors [1-3,25,29-31]. Among the later ones, review of the literature had shown important ones including the extent of exposure to individuals infected with the virus, fear of infecting family members, lack of access to testing and medical care for COVID-19, physical distancing, home confinement, quarantining, and loneliness, inconsistent messages and directives regarding public health measures such as wearing face masks, increased workloads, and economic hardships and insecurity. Being in a developing country, we could expect the impacts of worry, length of quarantine time, and the presence of special habits, on the current study cohorts.

Overall, the findings of the current study confirm the importance of "early" screening of COVID-19 patients for emotional distress, using a simple and valid tool like m-DT. This could have important clinical implications. Despite that psychiatric management of COVID-19 patients with significant distress may be beyond the scope of this paper, two observations related to our results deserve great attention. First, the COVID-19 pandemic has been associated with exacerbation of substance use behaviors and disorders [21,32]. An online, self-report survey of Chinese adults in March 2020 found that during the pandemic, the use of alcohol and tobacco increased [33]. Second, the COVID-19 pandemic may increase the risk of suicidal ideation and behavior, based upon studies that found previous viral epidemics were associated with increased rates of suicide deaths, including suicides that were reported as an adverse effect of quarantine [27,34]. Notably, suicidality related to COVID-19 may be due to the hardships imposed by the pandemic, including economic privation, social isolation, reduced access to general medical and mental health care, and the stigma of having COVID-19 [1-3,25,27-30].

Being the first two-center prospective study utilizing a modified DT in a relatively good number of patients does not guarantee that it has no limitations. Possible limitations include possible convenience sampling which may affect the generalizability of the study findings to all COVID-19 patients, and the study did not include patients admitted to the intensive care unit (ICU). Further studies are needed.

\section{Conclusion}

With the modified distress thermometer (m-DT), sixty percent of Egyptian COVID-19 patients experienced significant distress. This distress was significantly related to age, marital status, occupation, presence or absence of special habits, and length of the quarantine time. With m-DT, the current study had identified worry, being a health-care worker, shortness of breath, fever, quarantine time $>3$ months, presence of special habits, and cough as independent factors associated with significant distress in COVID-19 patients. We recommend further larger studies implementing this m-DT for screening COVID-19 patients for psychological distress. 


\section{Acknowledgments}

The authors thank Mr. Omar Sherif Mohamed (omard114@gmail.com), the research coordinator, for his great help in this manuscript.

$\begin{array}{ll}\text { Abbreviations } \\ \text { COVID-19: } & \text { Coronavirus disease 2019; } \\ \text { DT: } & \text { distress thermometer; } \\ \text { IPOS: } & \text { International Psycho-Oncology Society; } \\ \text { m-DT: } & \text { modified distress thermometer; } \\ \text { NCCN: } & \text { National Comprehensive Cancer Network; } \\ \text { NICE: } & \text { National Institute for Health and Care Excellence; } \\ \text { PL: } & \text { problem list; } \\ \text { PPE: } & \text { personal protective equipment; } \\ \text { SPSS: } & \text { Statistical Package for Social Science. }\end{array}$

\section{References}

1. Lai J, Ma S, Wang Y, Cai Z, Hu J, Wei N, et al. Factors associated with mental health outcomes among health care workers exposed to coronavirus disease 2019. JAMA Netw Open 2020;3:e203976.

2. Galea S, Merchant RM, Lurie N. The mental health consequences of COVID-19 and physical distancing: The need for prevention and early intervention. JAMA Int Med 2020;180:817-8.

3. Mohamed S, Elgohary G, Abd ElHaffez A, Kamel E, Abd ElAziz N. Does distress thermometer have a utility in the era of COVID-19 pandemic? Open Access Libr J 2020;7:e6643.

4. Holland JC, Anderson B, Breibart WS, Braun I, Breitbart WS, Brewer BW, et al. Distress management: Clinical practice guidelines in oncology. J Natl Compr Canc Netw 2013;11:190209.

5. Pirl WF, Fann JR, Greer JA, Braun I, Deshields T, Fulcher C, et al. Recommendations for the implementation of distress screening programs in cancer centers: Report from the American Psychosocial Oncology Society (APOS), Association of Oncology Social Work (AOSW), and Oncology Nursing Society (ONS) Joint Task Force. Cancer 2014;120:2946-54.

6. Abd El-Aziz N, Khallaf S, Abozaid W. Is it the time to implement the routine use of distress thermometer among Egyptian patients with newly diagnosed cancer? BMC Cancer 2020 20:1033.

7. Makuch M, Milanowska J, Michnar M, Makuch M, Samardakiewicz M, Milanowski J. The relationship between COPD assessment test (CAT) scores and distress thermometer (DT) Results in COPD patients. Ann Agric Environ Med 2020;27:689-94.

8. Trask PC, Paterson A, Riba M, Brines B, Griffith K, Parker P, et al. Assessment of psychological distress in prospective bone marrow transplant patients. Bone Marrow Transplant 2002 29:917-25.

9. Alosaimi FD, Abdel-Aziz N, Alsaleh K, Al Sheikh R, Al Sheikh R, Abdel-Warith A. Validity and feasibility of the Arabic version of distress thermometer for Saudi cancer patients. PLoS One 2018;13 e0207364.

10. Masoud HH, Elassal G, Zaky S, et al. Management protocol for COVID-19 patients, version 1.4, 30th May 2020. Ministry of Health and Population (MOHP), Egypt. May 2020. In: Coronavirus Disease 2019 (COVID-19), SARS-CoV-2 Management Guideline. Ministry of Health and Population. Available from: http://www.mohp.gov.eg/JobsDetails. aspx?job_id=3061

11. Riba MB, Donovan KA, Andersen B. Distress management, version 3.2019. NCCN clinical practice guidelines in oncology. J Natl Compr Cancer Netw 2019;17:1229-49.

12. Selim M, Mohamed S, Abdo M, Abdelhaffez A, Is COVID-19 similar in pregnant and non-pregnant women? Cureus 2020;12:e8888.

13. Selim MF, Mohamed SAA, Abdo M, Abdelhaffez A, et al. A case of postpartum mortality due to COVID-19 infection. J Med Case Rep Case Series 2020;1.

14. Mohamed S, Abo El-Hassan O, Rizk M, Ismail JH, Baioumy A. Death due to cardiac arrest in a young female with highly suspected COVID-19: A case report. Cureus 2020;12:e10127.

15. Mohamed S, Saad K, Elgohary G, AbdElHaffez A, Abd ElAziz N. Is COVID-19 a systemic disease? Coronaviruses 2020;1:1-5.

16. Mohamed S, Abd El-Mohsen S, Abo El-Hassan O, AbdElHaffez A, Abd El-Aziz N. Incidence and pathophysiologic mechanisms of stroke in the COVID-19 pandemic: the dilemma. Egypt J Bronchol 2020;14:31.

17. Roth AJ, Kornblith AB, Batel-Copel L, Peabody E, Scher HI, Holland JC. Rapid screening for psychologic distress in men with prostate carcinoma: a pilot study. Cancer 1998;82:1904-8.

18. Cutillo A, O'Hea E, Person S, Lessard D, Harralson T, Boudreaux E. The distress thermometer: Cutoff points and clinical use. Oncol Nurs Forum 2017;44:329336.

19. Hoffman BM, Zevon MA, D’Arrigo MC, Cecchini TB. Screening for distress in cancer patients: The NCCN rapidscreening measure. Psychooncology 2004;13:792-9.

20. Yao H, Chen JH, Xu YF. Patients with mental health disorders in the COVID-19 epidemic. Lancet Psychiatry 2020;7:e21.

21. Holmes EA, O'Connor RC, Perry VH, Tracey I, Wessely S, Arseneault L, et al. Multidisciplinary research priorities for the COVID-19 pandemic: a call for action for mental health science. Lancet Psychiatry 2020;7:547.

22. Rogers JP, Chesney E, Oliver D, Pollak TA, McGuire P, FusarPoli $\mathrm{P}$, et al. Psychiatric and neuropsychiatric presentations associated with severe coronavirus infections: a systematic review and meta-analysis with comparison to the COVID-19 pandemic. Lancet Psychiatry 2020;7:611-27.

23. Pierce M, McManus S, Jessop C, John A, Hotopf M, Ford T, et al. Says who? The significance of sampling in mental health surveys during COVID-19. Lancet Psychiatry 2020;7:567-8.

24. American Psychiatric Association [Internet]. New poll: COVID-19 impacting mental well-being: Americans feeling anxious, especially for loved ones; older adults are less anxious. Available from: https://www.psychiatry.org/ newsroom/news-releases/new-poll-covid-19-impacting-mental-well-being-americans-feeling-anxious-especially-forloved-ones-older-adults-are-less-anxious

25. McGinty EE, Presskreischer R, Han H, Barry CL. Psychological distress and loneliness reported by US adults in 2018 and April 2020. JAMA 2020;324:93-4.

26. Rossi R, Socci V, Pacitti F, Di Lorenzo G, Di Marco A, Siracusano A, et al. Mental health outcomes among frontline and second-line health care workers during the coronavirus disease 2019 (COVID-19) pandemic in Italy. JAMA Netw Open 2020;35:e2010185.

27. Kisely S, Warren N, McMahon L, Dalais C, Henry I, Siskind D. Occurrence, prevention, and management of the psychological effects of emerging virus outbreaks on healthcare workers: 
rapid review and meta-analysis. BMJ 2020;369:m1642.

28. Varatharaj A, Thomas N, Ellul MA, Davies NWS, Pollak TA, Tenorio EL, et al. Neurological and neuropsychiatric complications of COVID-19 in 153 patients: a UK-wide surveillance study. Lancet Psychiatry 2020;7:875-82.

29. Reger MA, Stanley IH, Joiner TE. Suicide mortality and coronavirus disease 2019-A perfect storm? JAMA Psychiatry 2020. Online ahead of print.

30. Brooks SK, Webster RK, Smith LE, Woodland S, Wessely S, Greenberg N, et al. The psychological impact of quarantine and how to reduce it: rapid review of the evidence. Lancet 2020;395: 912-20.
31. Xiang YT, Jin Y, Cheung T. Joint international collaboration to combat mental health challenges during the coronavirus disease 2019 pandemic. JAMA Psychiatry 2020;77:989-90.

32. Finlay I, Gilmore I. Covid-19 and alcohol-a dangerous cocktail. BMJ 2020;369:m1987.

33. Sun Y, Li Y, Bao Y, Meng S, Sun Y, Schumann G, Kosten T, et al. Brief Report: Increased addictive internet and substance use behavior during the COVID-19 pandemic in China. Am J Addict 2020;29:268-70.

34. Gunnell D, Appleby L, Arensman E, Hawton K, John A, Kapur $\mathrm{N}$, et al. Suicide risk and prevention during the COVID-19 pandemic. Lancet Psychiatry 2020;7:468-71. 